\title{
Stress of first postgraduate year leaves mark at cellular level for medical trainees
}

\author{
n Cite as: CMAJ 2019 July 8;191:E773-4. doi: 10.1503/cmaj.109-5770
}

Posted on cmajnews.com on June 19, 2019.

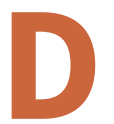

r. Michael Arget remembers the clinical training in his first year of medical residency as being mentally and physically exhausting. So it's no surprise that Arget, president of Resident Doctors of Canada and a resident in internal medicine at the University of Saskatchewan, was quick to send his colleagues a recent study showing that the first postgraduate year for medical trainees shortens their telomeres - the protective caps at the ends of chromosomes in cells. Telomeres normally shorten with age, but emerging research shows they can also shorten from stress. The length of telomeres is considered a biomarker for age and a risk factor for age-related diseases.

The stress of that first year (called an internship in the United State) was the focus of the research in 250 physiciansin-training, chosen from the first volunteers to enrol in a longitudinal cohort study on intern health that included more than 3000 trainees from 55 US hospital systems.

Telomeres of interns shortened measurably from the beginning of internship to the end, according to DNA tests. In fact, they shortened six times more than the population average for one year. Telomeres in a comparison group of nonmedical students actually lengthened.

However, a Canadian telomere researcher, Dr. Peter Lansdorp of the BC Cancer Research Centre, said many such studies are using an imprecise telomere analysis. "The results of this study need to be confirmed using more accurate telomere length measurements before they can be accepted," he said. The authors responded that their widely used method would not lead to systemic error in the results. As well, the same method was used twice in the same subjects, which adds to the validity of the measurements.

Other studies have shown that telomeres are shorter than expected in people experiencing stress, said Dr. Srijan Sen, a coauthor of the study and a researcher in depression and neurosciences at the University of Michigan. But those studies looked at one point in time rather than before and after a stressful experience.

"There are not a lot of situations that we know will be stressful," making such before-and-after studies difficult, he said. But medical internships fit the bill.

"It was a pretty dramatic increase in individuals in their 20s, where we don't see much telomere attrition at all." He said the study raises concern 
about the long-term effects of stress. "We only followed the interns during this year. It would be interesting to see how their telomeres are affected over many more years."

"We know that stress is a precipitant for depression and psychological illnesses, and an important predictor for heart attacks, strokes and autoimmune disorders," added Sen. "But we don't know the mechanism of how stress 'gets under the skin.' Hopefully, this is an important step in tracking that and in helping understand how that manifests through our biology and increases risk for disease."

Longer work hours were associated with shorter telomeres, the study found. Telomeres were markedly shorter in interns working 61-74 hours per week and even shorter in those working 75 hours or more. In the US, the American Council for Graduate Medical Education requires that shifts be no longer than 16 hours, for a maximum of 80 hours per week, including clinical work done from home.

In Canada, a 2018 survey of residents found that $72 \%$ worked more than 60 hours per week and almost $20 \%$ reported 80 or more hours, said Arget. There is no panCanadian limit on weekly duty hours. However, most collective agreements limit oncall periods to 24 to 26 hours. In Quebec, the maximum is 16 consecutive hours after an arbitrator ruled in 2011 that 24-hour shifts violated residents' rights.

According to Arget, pressure on residents is increasing. "This highlights an ongoing challenge across the country, as residency spots are shrinking. As a result, there is even more of a push for residents to fill in the gap and take on more roles and responsibilities. That was never accepted before because there were more bodies."

Resident Doctors of Canada has worked with the Canadian Mental Health Association to develop a resiliency curriculum "giving residents skills and tools for self-reflection for when they are well or not well" that is being rolled out in medical schools.

Sen says more needs to be done. "I hope our study adds to the evidence to limit hours. In both Canada and the US, residents are going to work longer hours than the typical workers, but it's important to keep it at the lower end of the range."

Carolyn Brown, Ottawa, Ont. 